\title{
RESEÑA: RELIGIÓN Y JUVENTUD. EL IMPACTO DE LOS CAMBIOS SOCIOCULTURALES EN LOS PROCESOS DE TRANSMISIÓN DE LA FE, DE LUIS BAHAMONDES, NELSON MARÍN, LUIS ArÁnguiz y FLOREnCIA Diestre (2020) ${ }^{1}$
}

\author{
JoSÉ MANZANO PAVEZ
}

La presente reflexión surge desde la lectura del trabajo de Bahamondes, Marín, Aránguiz y Diestre (2020), en el que se analiza cómo los cambios sociales, culturales y políticos, desde la vuelta a la democracia en Chile, han incidido en el proceso de transmisión de la fe católica en jóvenes que asisten a establecimientos escolares y universidades.

Este trabajo se posiciona desde una metodología cualitativa, pues buscaba conocer las diferentes percepciones y experiencias de un diverso grupo de estudio, así como su relación con la Iglesia, la fe y la educación católica. La información se recogió a partir de sesenta entrevistas semiestructuradas y grupos de conversación, donde participaron padres, estudiantes de colegios católicos y universitarios de instituciones laicas y confesionales de la Región Metropolitana, considerando criterios de sexo, edad, nivel socioeconómico (NSE; bajo, medio y alto), nivel educativo (séptimo y octavo básico, tercero y cuarto medio) y el tipo de fe de cada participante, caracterizada entre activa y pasiva. Para el análisis de

\footnotetext{
${ }^{1}$ Ediciones Universidad Alberto Hurtado, Santiago de Chile, 2020.

${ }^{2}$ Licenciado en Antropología, mención Antropología Social. Integrante del Núcleo de Investigación y Acción en Juventudes, Departamento de Sociología, Universidad de Chile. Correo electrónico: jose.manzano@ug.uchile.cl
} 
la información, se recurrió al Análisis de Discurso, pues «permite realizar un balance respecto al modo en que la cuestión de la fe católica y su transmisión es construida» (p. 28). De esta manera, la presentación de los resultados se estructuró en cinco capítulos.

En el primer capítulo, los autores reflexionan, a partir de la revisión de diferentes informes e investigaciones nacionales e internacionales, sobre el recorrido de los principales cambios sociales y culturales de las últimas tres décadas en Chile, y cómo estos han modificado, en diferentes niveles, la adhesión de los jóvenes católicos chilenos a las prácticas religiosas. Dentro de estos cambios que señalan se encuentra la ampliación de la cobertura en la Educación Superior, el consumo cultural asociado al acceso a las tecnologías de comunicación e información y el sentimiento de inseguridad económica, en lo que respecta a la precarización del trabajo. Dichos cambios tienen consecuencias directas en la sociedad, principalmente por el desarrollo de un «contexto de individualización y debilitamiento de referentes tradicionales» (p. 35), que permite la apertura a nuevas formas de religiosidad desancladas de las estructuras clásicas. Por otro lado, se dan puntos para el análisis particular de las prácticas religiosas en jóvenes, debiendo considerar su complejidad en cuanto «se expresa en la multiplicidad de formas de pertenecer y adherir a sistemas de creencias (completa o parcialmente) e instituciones religiosas (tradicionales o emergentes)» (p. 43), lo que configura un campo de análisis cruzado por diferentes condiciones y limitantes estructurales y agenciales.

Luego, en el segundo capítulo, los autores proponen detenerse a realizar una lectura sobre las representaciones que tienen los jóvenes sobre la Iglesia, la fe, la forma de vivirla y su transmisión. Estableciendo los criterios de análisis, sugieren hacer distinciones claves para una mejor comprensión de la diversidad de perspectivas entre los jóvenes entrevistados, considerando la variedad en torno al NSE y distinguiendo las percepciones entre secundarios y universitarios. Respecto a la transmisión de la fe, es necesario observar este proceso desde el diálogo intergeneracional, pues los núcleos familiares se consideran como los espacios relacionales centrales para la socialización de las prácticas religiosas que los jóvenes pudieran adherir y replicar. En tanto a las representaciones de la Iglesia y la fe, se pone en relieve un problema comunicacional entre la definición de fe según la Iglesia, fundamentado teológicamente, y las concepciones juveniles contemporáneas que se escapan, en la mayoría de las veces, de la catequesis eclesial, generando así un escenario donde nuevas formas de vivir la fe, sin reducirla a la cristiana, tanto para creyentes como ateos, son reconocidas. 
Las experiencias de significación de la Iglesia tampoco se limitan a cuestiones de índole institucional, sino que se destaca la relevancia del sentido comunitario y de la acción social, concibiendo a la Iglesia «como un espacio en que la fe se puede vivir de manera lúdica en tanto que haya participación juvenil» (p. 69).

El tercer capítulo versa sobre la transmisión de la fe que se da al interior de la familia. Dicho grupo humano se constituye como la unidad básica de la Iglesia que, durante siglos, ha proyectado un modelo rígido, donde todas las partes tienen su función y la ausencia de alguna de ellas prevería hacia el fracaso en diversos ámbitos de la vida social para sus miembros. Sin embargo, la transmisión de la fe en los actuales tiempos de la posmodernidad pone en absoluta tensión el modelo cristiano de la familia, pues el reconocimiento público de distintos tipos de familias ha deconstruido la estructura clásica. En este contexto, desde la psicología de la religión es posible observar que «la influencia de la religiosidad de los padres es más significativa que la estructura familiar en la que el adolescente se desenvuelve» (p. 103), lo que pondría en relevancia a la agencia y las motivaciones individuales por sobre a una estructura única y estática como motor de transmisión de la fe. Otro punto para considerar, y que es destacado por los autores, es la preminencia del adultocentrismo en la comprensión de la transmisión de la fe al interior de las familias, pues se asume que los adultos actúan en tanto emisores y sus hijos como meros receptores, sin posibilidad de transformación y decisión sobre las prácticas religiosas y el desarrollo autónomo de una espiritualidad. En el curso de la investigación se destaca que los padres entrevistados reconocen los acelerados cambios culturales, descritos en el primer capítulo, que hacen que tengan que ceder ante la incompatibilidad de códigos que les gustaría compartir con sus hijos sobre la fe, siendo muy difícil su imposición obligatoria, por lo que deciden enfrentar la transmisión desde la flexibilidad y el diálogo de diversos temas, como de la contingencia política o la multiculturalidad (p. 117). En este capítulo permanece el potencial de discutir tanto la fe como el acercamiento a la Iglesia desde una perspectiva generacional, puesto que la familia ya no se concibe como la única forma de socialización religiosa, sino que surgen otros espacios como el colegio, las pastorales juveniles, los movimientos y los grupos de scout, donde muchas veces por la confianza, la amistad y la proximidad etaria es posible elaborar prácticas religiosas diferentes a las tradicionales, o bien, resignificar estas.

El cómo las instituciones educacionales religiosas influyen en la transmisión de la fe es la pregunta principal del cuarto capítulo de la investigación. En un contexto de secularización de las relaciones de la vida 
político-social, los autores realizan una diferencia entre los contextos escolares y universitarios. En los primeros, la existencia de instancias formativas, como las pastorales y las clases de religión, fomentan la socialización religiosa de los estudiantes, y son destacados por ellos (p. 128), junto con otras actividades no explícitamente religiosas, como grupos deportivos y de scout; la estructura escolar puede conducir una determinada forma de promover la fe, debido al mayor control que posee sobre sus miembros. Por otra parte, en los contextos universitarios, «los espacios de cultivo de la fe son percibidos como restringidos, en tanto no existe una oferta como la que entregan los colegios y además la misión no corresponde a una intencionadamente religiosa» (p. 130); sobre esta situación, el ambiente universitario promovería una sensación de libertad entre los jóvenes que permearía en la reserva del desarrollo de sus intereses religiosos, trasladándolos a un nivel más privado y exterior, situación que sucede tanto en instituciones laicas como católicas. Cerrando el capítulo se ahonda en una caracterización de las instituciones educativas jesuitas, siendo la promoción de la acción social y la acogida de minorías el énfasis frente a estudiantes de otros proyectos educativos católicos, que vendrían a trabajar más con el ámbito sacramental de la fe (p. 136).

Para finalizar el cuerpo de la investigación, el jesuita y académico Cristóbal Madero SJ realiza una reflexión empírica sobre los establecimientos escolares católicos en Chile, respecto a las proyecciones sobre la transmisión de la fe, a través de la aplicación de sesenta entrevistas semiestructuradas a estudiantes de establecimientos educacionales católicos de Santiago. El texto comienza con un recorrido histórico sobre la educación católica en el país desde los inicios de la República hasta la actualidad, puntualiza desafíos claves para la escuela católica, que van desde la escasa producción en investigación sobre este espacio, los objetivos del mismo, las dificultades de las clases de religión en la creciente secularización global, la formación de docentes que imparten esa asignatura y la responsabilidad de reconocer la pérdida de credibilidad y confianza a la Iglesia desde los casos de abuso sexual por parte de sacerdotes y religiosos, entendiéndolas como prácticas sistemáticas (p. 154). Continúa el texto con una crítica a la investigación presentada, desde la instalación de la individualización de la experiencia religiosa de los jóvenes en la escuela, en el sentido de que la expresión "no es bien visto ser católico" es compartida por muchos jóvenes en el estudio (p. 156). La posibilidad de que los jóvenes pueden vivir la fe se funda en relaciones intrageneracionales que le otorgan sentido, en oposición a lo que ocurre afuera, donde se produce un desfase generacional en espacios tan tradicionales para la Iglesia como la misa, donde los jóvenes no se 
pueden encontrar con otros similares, sino con adultos mayores, situación que no les otorga un sentido significativo. Termina mencionando algunas proyecciones sobre cómo abordar los desafíos, que menciona en un inicio, que tiene la escuela católica actual para los tiempos de secularización, como la formación permanente y actualizada de los docentes de Religión, y la promoción de actividades que promuevan la vivencia de lo religioso, más allá de lo sacramental, como espacios deportivos y el escoutismo, como se indica, «para algunos estudiantes entrevistados, bastó solo una oración al inicio de un partido para darle un sentido religioso a la experiencia completa» (p. 163).

El problema de las generaciones, por un lado, y el diálogo de los jóvenes con las instituciones educativas y la Iglesia, por otro, resultan las principales aristas que permiten generar una reflexión crítica sobre las juventudes en el Chile contemporáneo. En primer lugar, es importante destacar la tensión generacional que se percibe al interior de una institución como la Iglesia católica, donde tanto niños, niñas, jóvenes, adultos y adultos mayores coexisten en su desarrollo y misión evangelizadora. Esta colisión de edades conlleva a una disputa por los espacios, como la misa, la calle, el juego, la política y la escuela, entre otros, extendiendo y retrayendo las fronteras entre unas generaciones y otras (Criado, 1998). El trabajo comentado permite indicar la existencia de espacios capitalizados por ciertas clases de edad, donde el resultado de esta relación se traduciría en la producción de los mismos sujetos.

En la misma dirección, la relación de los jóvenes con las instituciones educativas $\mathrm{y}$, particularmente, la Iglesia, requiere reconocer a esta como un espacio históricamente construido sobre la base del adultocentrismo, tanto por sus orígenes judaicos como por el desarrollo de una tradición que relega a los niños, niñas y jóvenes a un proceso unidireccional de maduración personal, moral y espiritual. Por medio de una relación de dominación basado en las edades, el grupo dominado acepta y aprehende esta asimetría, en tanto la Iglesia, como institución de los adultos, establece códigos y patrones de conducta que son continuamente perfeccionados para legitimar su discurso de poder (Duarte, 2019). En el trabajo comentado, es posible materializar dicha relación a partir de los límites de las instituciones educativas donde circulan los participantes de la investigación, la ausencia de un interés por la identificación católica por parte de algunos jóvenes, así como el descarte de ciertas prácticas donde reconocen distancia con generaciones adultas, por lo tanto con la tradición, poniendo en tensión la perdurabilidad de la Iglesia en el tiempo, así como la necesidad de innovación en los procesos de transmisión de la fe. 
Esta investigación abre espacio a la discusión de un campo no tan explorado en el contexto chileno y latinoamericano, como lo es la vinculación entre religiones y juventudes, si bien desde una particularidad en realidades educativas específicas, la posibilidad de seguir indagando comparativamente, como en relación con el género y el territorio, hace que este trabajo sea referencial para la elaboración de preguntas de investigación. En tanto alcances teóricos y metodológicos, un abordaje generacional seguiría sosteniendo la discusión sobre temas como la evangelización, el secularismo y las disputas de poder en espacios públicos y privados, con el sujeto joven como protagonista.

\section{BIBLIOGRAFÍA}

CRIADO, E. (1998). Producir la juventud. Critica de la sociología de la juventud. Madrid: Ediciones Istmo.

DuARTE, K. (2019). Trastrocaciones adultocéntricas y criterios políticos para la igualdad generacional. En K. DuARTE, N. HeRnándeZ y Y. PALENZUELA (Eds.), Juventudes en Chile. Miradas de jóvenes que investigan, vol. 2, (pp. 19-38). Santiago de Chile: Social-Ediciones. 